\title{
Allergic Rhinitis Therapy Decisions During a Routine Consultation: A Multicenter, Cross-Sectional Survey
}

This article was published in the following Dove Press journal: Journal of Asthma and Allergy

\author{
Gabriella Gálffy $\mathbb{D}^{1}$ \\ Melanie Emmeluth ${ }^{2}$ \\ Arkady Koltun (iD) ${ }^{3}$ \\ Ferdinand Kopietz $\mathbb{D}^{2}$ \\ Duc Tung Nguyen ${ }^{2}$ \\ Hans Christian Kuhl ${ }^{2}$ \\ 'Onco-Pulmonology Department, Pest \\ County Pulmonology Hospital, \\ Törökbálint, Hungary; ${ }^{2}$ Global Medical \\ Affairs, MEDA Pharma GmbH \& Co. KG \\ (A Mylan Company), Bad Homburg, \\ Germany; ${ }^{3}$ Global Medical Affairs, Mylan, \\ Inc, Canonsburg, PA, USA
}

Correspondence: Gabriella Gálffy

Head of the Onco-Pulmonology

Department and Research and Education

Director of Pest County Pulmonology

Hospital, Törökbálint 70, Munkácsy

Mihály Street, Törökbálint, 2045, Hungary

Fax +36-235II598

Email ggalffy@hotmail.com
Background: Allergic rhinitis (AR) is characterized by nasal and ocular symptoms, and substantially impacts the quality of life. Therapy selection for patients with AR depends on several factors, including symptom severity, age, patient preference, patient adherence, and cost.

Methods: The purpose of this multicenter, noninterventional, cross-sectional survey was to evaluate current therapy decisions in routine clinical practice for patients with symptomatic $\mathrm{AR}$, and to determine how these decisions are linked to experiences with previous treatments and current symptom severity as assessed by aVAS. The survey included patients aged 18 years or older in Spain and 12 years or older in Hungary who consulted a physician for treatment of AR symptoms. Physicians recorded AR symptom burden in the previous 7 days, previous AR treatments, and the current AR therapy decision made at the visit.

Results: Overall, $72.9 \%$ of 181 patients (Spain) and $67.1 \%$ of 228 patients (Hungary) had received treatment in the previous 7 days. Among patients who had received step 3 treatment, $82.9 \%$ (Spain) and $75.8 \%$ (Hungary) received a free combination of intranasal corticosteroid (INCS) and antihistamines. Despite the high number of pretreated patients in both countries, $72.9 \%$ and $78.9 \%$ in Spain and Hungary, respectively, reported uncontrolled symptoms (VAS $\geq 50 \mathrm{~mm}$ ). Of pretreated patients, 58.3\% (Spain) and $61.4 \%$ (Hungary) received a step-up in treatment during the visit. Physicians more often prescribed a fixed combination of INCS and intranasal antihistamine than a free combination. However, of patients with uncontrolled symptoms who received previous therapy, 28.0\% (Hungary) and $40.6 \%$ (Spain) did not receive a step-up as suggested by the guidelines.

Conclusion: Many patients suffering from acute AR symptoms consulted with their physician because of insufficient medications. Not all patients with uncontrolled symptoms received a step-up in treatment, underscoring the need for improved physician education to enhance AR management and control in accordance with consensus treatment guidelines.

Keywords: allergic rhinitis, therapy, decision-making, guidelines, intranasal corticosteroid, antihistamine, visual analog scale, noninterventional

\section{Background}

Allergic rhinitis (AR) is characterized by nasal symptoms, including congestion, itching, rhinorrhea, and sneezing, and it is often associated with ocular symptoms, such as itchy, watery eyes and redness. ${ }^{1}$ AR has been shown to negatively impact productivity and quality of life, including the occurrence of emotional problems and the impairment of sleep, social functioning, daily life activities, and work and 
school productivity. ${ }^{1}$ In fact, global loss of work productivity because of AR has been shown to be significantly greater than that due to hypertension and diabetes mellitus. ${ }^{1,2}$ AR can be complicated with comorbidities of both the upper and lower airways, including rhinosinusitis and asthma, which may contribute to the reported impact on productivity and quality of life. ${ }^{3}$

In a survey of over 500 European participants, nearly $50 \%$ reported sleep issues related to their $\mathrm{AR}^{4}{ }^{4}$ The AR symptoms most frequently reported to affect sleep were stuffy/runny nose or itching of the nose/palate and other head symptoms. ${ }^{4}$ Furthermore, poor sleep was demonstrated to have an impact on work attendance, productivity, and nonwork activity, with an average of $12.0 \%$ of work time missed over the past 7 days, $46.9 \%$ impairment while working (presenteeism), 53.3\% overall work impairment, and $47.1 \%$ non-work-related activity impairment. ${ }^{4}$ A cross-sectional analysis revealed that self-reported AR was significantly associated with higher total lost productive time, defined as the combination of absenteeism and presenteeism. ${ }^{5}$

Early control of AR is needed; however, physicians may underestimate patients' symptom burden, which can lead to potential undertreatment or mismanagement of the disease. ${ }^{6}$ AR treatment selection is based on symptoms, symptom severity, patient preferences, availability, and cost. $^{7}$ A knowledge-based clinical decision support system has been developed. ${ }^{8}$ This system is based on visual analog scale (VAS) measurements, which are used to make step-up or step-down decisions about treatment.

Often, AR severity is assessed using VAS, which is a validated instrument that is simple and widely used. The best cut-off VAS scores for differentiating among mild, moderate, and severe disease have been identified as 40 and 70 on a scale of 0 to 100 . Importantly, the VAS values defined by MACVIA/ARIA related to AR control include cut-off points at $>50 \mathrm{~mm}$ for uncontrolled disease, $20-50 \mathrm{~mm}$ for partly controlled disease, and $<20 \mathrm{~mm}$ for well-controlled disease. ${ }^{9}$ The use of $50 \mathrm{~mm}$ as a cut-off in this survey for assessing patients with uncontrolled disease is supported by the same VAS score used to indicate moderate to severe AR in previous studies. ${ }^{10,11}$

Current 2019 ARIA guidelines recommend the following treatments: step 1 - nonsedating H1-antihistamine (oral, intranasal, ocular), leukotriene receptor antagonists, or cromones (intranasal, ocular); step 2 - intranasal corticosteroid (INCS); step 3 - INCS plus intranasal azelastine; step 4 - oral corticosteroid as a short course and an add-on treatment; step 5 - consider referral to a specialist and allergen immunotherapy. ${ }^{7}$

While the guidelines clearly delineate a treatment continuum, patients who are nonadherent to their current treatment may not need intensification of treatment if they were to take their medication according to instruction. More than $40 \%$ of patients prescribed medication for AR are not adherent to their treatment plan. ${ }^{12}$ Lack of medication adherence can lead to poor symptom control in $\mathrm{AR},{ }^{13}$ and poor response to treatment should always prompt clinicians to assess adherence prior to changes in the treatment plan. ${ }^{14}$ Furthermore, shared decision-making is an important strategy to improved medication adherence. In addition, patient education and counseling are needed on the benefits of medication (eg, improved quality of life with symptom control), ${ }^{15-17}$ as well as discussion regarding common causes of poor adherence, such as false expectations, concerns about treatment safety, past or potential side effects, and cost or lack of access to medications. ${ }^{10,18}$

The current survey was designed to evaluate AR therapy decisions in routine clinical practice and to determine how these decisions are linked to experiences with previous treatments and current symptom severity as assessed by VAS.

\section{Methods \\ Study Population}

Patients aged 18 years or older (Spain) and 12 years or older (Hungary) who were previously diagnosed with AR and were consulting a physician for treatment of AR symptoms were considered for inclusion. Based on Spanish legislation, only patients aged 18 years or older could be enrolled. Only those patients experiencing acute symptoms on the day of consultation, as determined by the participating physician, were included in the convenience sample. There were no restrictions regarding concomitant medications.

Participating physicians included general practitioners, ear, nose and throat (ENT) specialists, pulmonologists, dermatologists, and pediatricians. Physicians had to be using VAS routinely for AR symptom assessment as recommended by MACVIA/ARIA guidelines. Each physician/center could document up to 100 patients. There were 4 participating physicians.

\section{Survey Design}

In this multinational, multicenter, cross-sectional, noninterventional survey, there was 1 day of documentation 
when a patient visited the physician for treatment of AR symptoms. The decision to include a patient was made by the physicians independent of the treatment decision. After obtaining signed informed consent forms from participants or guardians, the following were recorded: demographic data and history of AR, AR treatments used within the last 7 days as reported by patients, the current AR therapy decision, and AR symptom severity measured via VAS. The first patient was recruited on October 3, 2018, and the visit of the last patient occurred on April 29, 2019.

\section{Symptom Assessment}

Physicians recorded how bothersome overall AR symptoms were in the previous 7 days, as documented by each patient on the VAS ( $0 \mathrm{~mm}$, not at all bothersome; $100 \mathrm{~mm}$, extremely bothersome) during the consultation visit. Physicians recorded the AR treatment prescribed during the visit, which could include the following: intranasal H1antihistamine, intranasal decongestant, intranasal mast cell stabilizer, INCS, a fixed combination of INCS, and antihistamine, oral decongestant, oral H1antihistamine $(\mathrm{OAH})$, oral leukotriene antagonist, oral or nebulized corticosteroid, ocular H1-antihistamine, ocular mast cell stabilizer, any other, or unknown.

\section{Therapy Description}

AR therapies were categorized into steps adapted from the MACVIA clinical decision algorithm-the current guideline at the time of the study-as follows: step 1 - for mild symptoms, intranasal or oral nonsedating H1-antihistamine; step 2 - for moderate to severe symptoms and/or persistent AR, INCS (the dose of some INCS therapies can be increased according to the package insert); step 3 - for patients with uncontrolled symptoms at step 2 (current or historical), combination of INCS and intranasal H1-antihistamines (depending on the physician's experience, other therapeutic strategies could be used); step $3 \mathrm{a}$ - free combination of Intranasal antihistamine (INAH)/OAH plus INCS; step $3 \mathrm{~b}$ - fixed combination of INCS plus INAH; step 4 - it is possible that an additional short course of oral steroids may help to establish control and continue control by step 3 (intraocular cromones or H1-antihistamines may be added to improve the control of ocular symptoms). Each successive step represented an increase in treatment intensity. ${ }^{7,8}$

\section{Adverse Events}

Adverse drug reactions were documented. Causality assessment was required for any adverse drug reaction.
All cases judged by the reporting healthcare professional or by the sponsor as having a reasonable suspected causal relationship to the product qualified as adverse drug reactions.

\section{Subpopulations}

Data were analyzed in the overall population and in the following prespecified subpopulations (SP) if they corresponded to approximately $10 \%$ or more of the overall population. SP1: patients with no previous AR treatment within the last 7 days (untreated); SP2: patients with at least 1 previous AR treatment within the last 7 days (pretreated); SP3: patients with VAS $<50 \mathrm{~mm}$; SP4: patients with VAS $\geq 50 \mathrm{~mm}$; SP5: patients with VAS $<50 \mathrm{~mm}$ and untreated; SP6: patients with VAS $<50 \mathrm{~mm}$ and pretreated; SP7: patients with VAS $\geq 50 \mathrm{~mm}$ and untreated; SP8: patients with VAS $\geq 50 \mathrm{~mm}$ and pretreated.

Table I Patient Subpopulation Distribution - Spain

\begin{tabular}{|c|c|c|c|}
\hline Subpopulation & Description & $\begin{array}{l}\text { Total } \\
\text { Number }\end{array}$ & $\begin{array}{l}\% \text { of } \\
\text { Overall } \\
\text { Population }\end{array}$ \\
\hline Subpopulation I & $\begin{array}{l}\text { Patients with no } \\
\text { previous AR } \\
\text { treatment within last } \\
7 \text { days (untreated) }\end{array}$ & 49 & 27.1 \\
\hline Subpopulation 2 & $\begin{array}{l}\text { Patients with } \geq 1 \\
\text { previous AR } \\
\text { treatment within last } \\
7 \text { days (pretreated) }\end{array}$ & 132 & 72.9 \\
\hline Subpopulation 3 & $\begin{array}{l}\text { Patients with VAS } \\
<50 \mathrm{~mm}\end{array}$ & 49 & 27.1 \\
\hline Subpopulation 4 & $\begin{array}{l}\text { Patients with VAS } \\
\geq 50 \mathrm{~mm}\end{array}$ & 132 & 72.9 \\
\hline Subpopulation 5 & $\begin{array}{l}\text { Patients with VAS } \\
<50 \mathrm{~mm} \text { and } \\
\text { untreated }\end{array}$ & 18 & 9.9 \\
\hline Subpopulation 6 & $\begin{array}{l}\text { Patients with VAS } \\
<50 \mathrm{~mm} \text { and pre- } \\
\text { treated }\end{array}$ & 31 & 17.1 \\
\hline Subpopulation 7 & $\begin{array}{l}\text { Patients with VAS } \\
\geq 50 \mathrm{~mm} \text { and } \\
\text { untreated }\end{array}$ & 31 & 17.1 \\
\hline Subpopulation 8 & $\begin{array}{l}\text { Patients with VAS } \\
\geq 50 \mathrm{~mm} \text { and } \\
\text { pretreated }\end{array}$ & 101 & 55.8 \\
\hline
\end{tabular}

Note: Percentage refers to total population $(\mathrm{N}=181)$. 


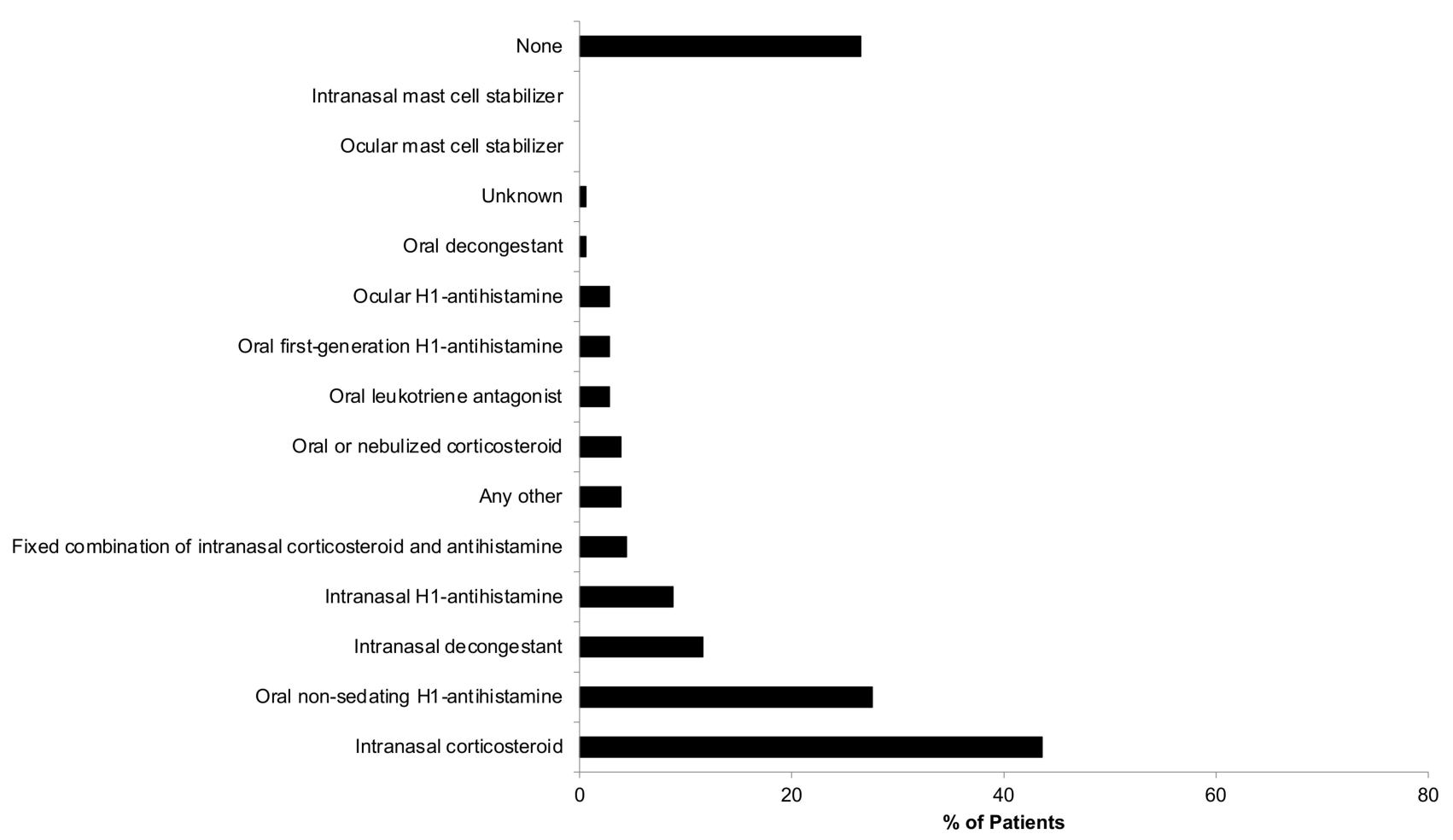

Figure I Previous symptomatic AR treatments within the last 7 days - Spain. Multiple entries were possible.

\section{Statistical Analysis}

Continuous variables were summarized by number, mean, standard deviation (SD), minimum, 5th percentile, lower quartile, median, upper quartile, 95th percentile, and maximum. Categorical variables were presented using frequency distribution tables with numbers and percentages. Data analysis was descriptive; therefore, no statistical tests were planned. SAS 9.4 software was used for data management and calculations.

\section{Results}

\section{Spain}

Overall, data from 211 patients were documented. Patients were excluded because of a lack of confirmed data or missing therapy decisions $(n=25)$ or because of age $<18$ years $(\mathrm{n}=5)$. Of the patients included in the study $(\mathrm{N}=$ 181), 114 were female (63\%). Most patients were aged 18 to 64 years $(171 ; 94.5 \%)$, with 10 patients aged 65 years or older. The mean age was 41.5 years (range, 18-76 years). Within the previous 7 days, $72.9 \%$ of patients had received at least $1 \mathrm{AR}$ treatment. The average duration of AR was 12.8 years. Subpopulations are described in Table 1.

A total of 49 patients $(27.1 \%)$ had received no treatment within the last 7 days, whereas $42(23.3 \%)$ patients were treated according to step $1 ; 42(23.2 \%)$ patients were treated according to step 2; $41(22.7 \%)$ patients were treated according to step 3 ; and 7 patients (3.9\%) were treated according to step 4. Among those patients treated according to step 3, 34 $(82.9 \%)$ received a free combination of intranasal corticosteroid and oral or intranasal antihistamine (step 3a), and 7 patients $(17.1 \%)$ received a fixed combination of intranasal corticosteroid and antihistamine (step 3b). Previous AR treatments are shown in Figure 1.

Among patients who rated their symptoms as $<50 \mathrm{~mm}$ on the VAS, most patients had received no treatment in the previous 7 days, followed by step 2 medication (Table 2). Among patients who rated their AR symptoms as $\geq 50 \mathrm{~mm}$ on the VAS, similar proportions of patients had received no treatment, step 1 medication, step 2 medication, and step 3 medication (Table 2).

Table 2 Previous Treatment per Step in Subpopulations - Spain

\begin{tabular}{|l|l|l|}
\hline $\mathbf{N}$ (\%) & $\begin{array}{l}\text { SP3: VAS }<\mathbf{5 0} \mathbf{~ m m} \\
\mathbf{N}=\mathbf{4 9}\end{array}$ & $\begin{array}{l}\text { SP4: VAS } \geq \mathbf{5 0} \mathbf{~ m m} \\
\mathbf{N}=\mathbf{~ I 3 2}\end{array}$ \\
\hline $\begin{array}{l}\text { No } \\
\text { treatment }\end{array}$ & $18(36.7)$ & $31(23.5)$ \\
Step I & $8(16.3)$ & $34(25.8)$ \\
Step 2 & $13(26.5)$ & $29(22.0)$ \\
Step 3 & $8(16.3)$ & $33(25.0)$ \\
Step 4 & $2(4.1)$ & $5(3.8)$ \\
\hline
\end{tabular}




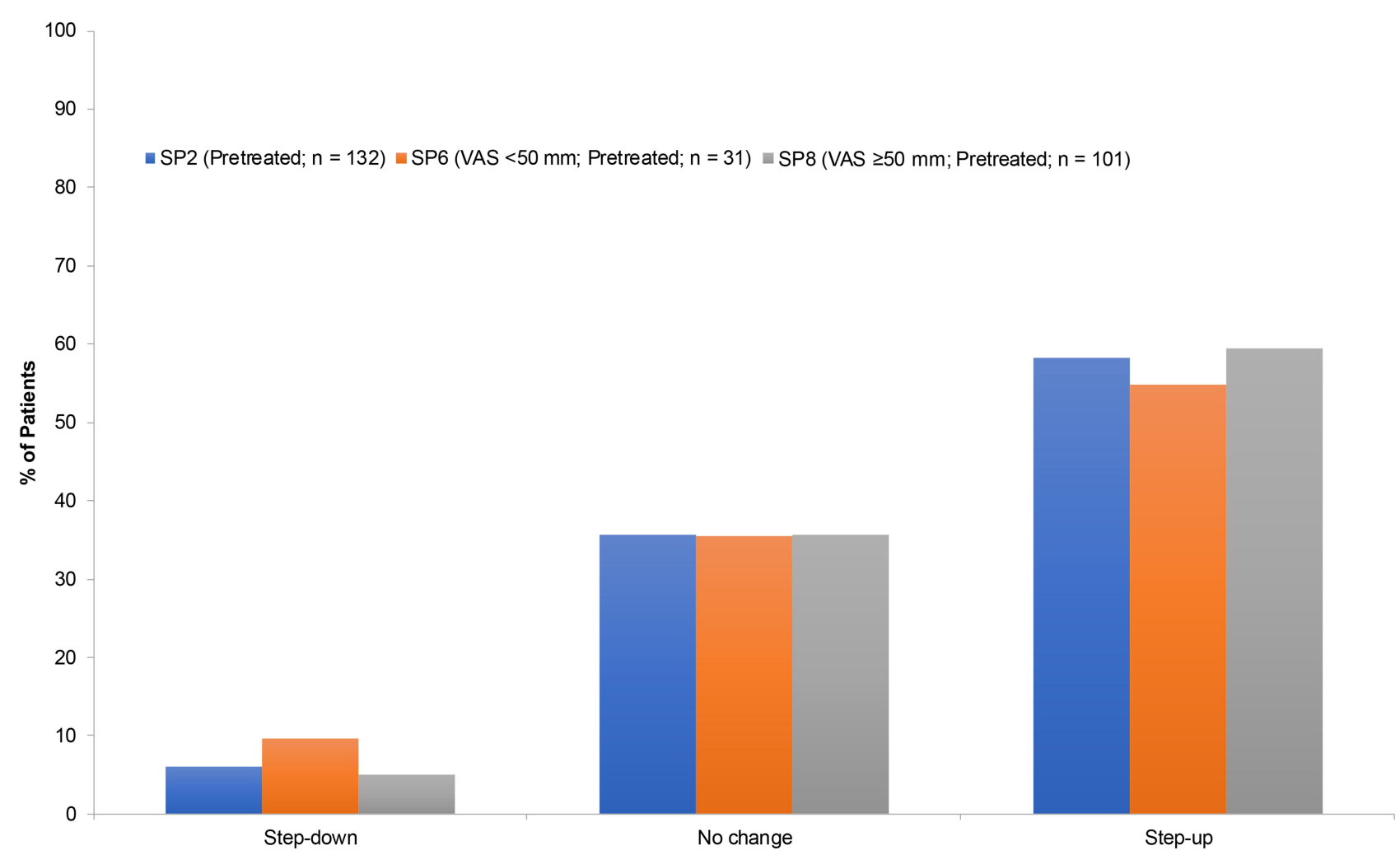

Figure 2 Change of AR treatment during the visit - Spain.

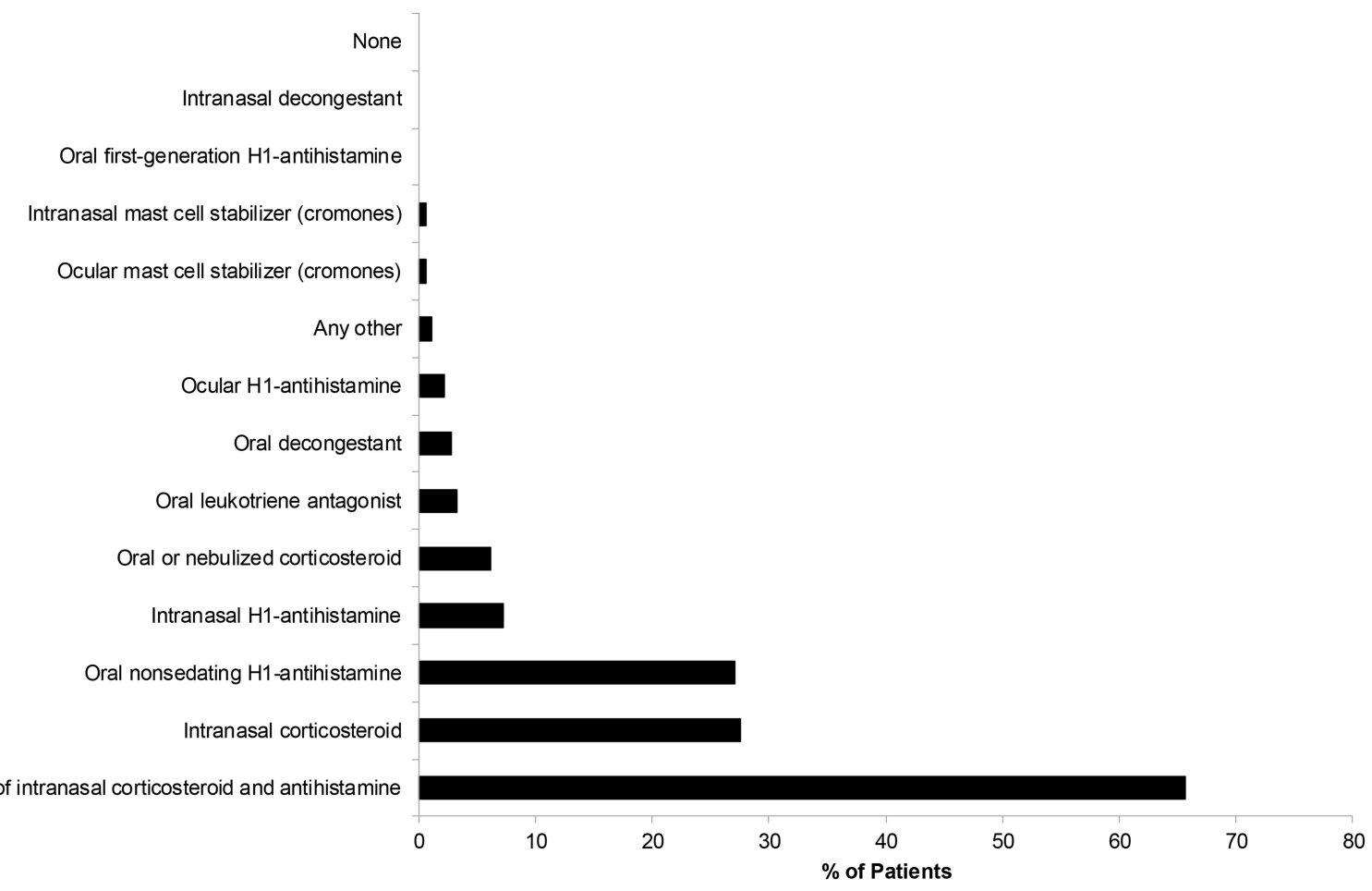

Figure 3 List of AR treatments prescribed during the visit - Spain. 
Table 3 Patient Subpopulation Distribution - Hungary

\begin{tabular}{|c|c|c|c|}
\hline Subpopulation & Description & $\begin{array}{l}\text { Total } \\
\text { Number }\end{array}$ & $\begin{array}{l}\% \text { of } \\
\text { Overall } \\
\text { Population }\end{array}$ \\
\hline Subpopulation I & $\begin{array}{l}\text { Patients with no } \\
\text { previous AR } \\
\text { treatment within last } \\
7 \text { days (untreated) }\end{array}$ & 75 & 32.9 \\
\hline Subpopulation 2 & $\begin{array}{l}\text { Patients with } \geq 1 \\
\text { previous AR } \\
\text { treatment within last } \\
7 \text { days (pretreated) }\end{array}$ & 153 & 67.1 \\
\hline Subpopulation 3 & $\begin{array}{l}\text { Patients with VAS } \\
<50 \mathrm{~mm}\end{array}$ & 48 & 21.1 \\
\hline Subpopulation 4 & $\begin{array}{l}\text { Patients with VAS } \\
\geq 50 \mathrm{~mm}\end{array}$ & 180 & 78.9 \\
\hline Subpopulation 5 & $\begin{array}{l}\text { Patients with VAS } \\
<50 \mathrm{~mm} \text { and } \\
\text { untreated }\end{array}$ & 13 & 5.7 \\
\hline Subpopulation 6 & $\begin{array}{l}\text { Patients with VAS } \\
<50 \mathrm{~mm} \text { and } \\
\text { pretreated }\end{array}$ & 35 & 15.4 \\
\hline Subpopulation 7 & $\begin{array}{l}\text { Patients with VAS } \\
\geq 50 \mathrm{~mm} \text { and } \\
\text { untreated }\end{array}$ & 62 & 27.2 \\
\hline Subpopulation 8 & $\begin{array}{l}\text { Patients with VAS } \\
\geq 50 \mathrm{~mm} \text { and } \\
\text { pretreated }\end{array}$ & 118 & 51.8 \\
\hline
\end{tabular}

Note: Percentage refers to total study population $(\mathrm{N}=228)$.

During the visit, $140(77.3 \%)$ patients were prescribed step 3 treatment, $19(10.5 \%)$ were prescribed step 2 treatment, 19 (8.3\%) were prescribed step 1 treatment, and 11 (6.1\%) patients each were prescribed step 1 and step 4 treatment. Among those prescribed step 3 treatment, $80.0 \%$ were prescribed a fixed combination, and $28.0 \%$ were prescribed a free combination of intranasal corticosteroid and oral or intranasal antihistamine.

The change of AR treatment during the visit in pretreated patients (subpopulation 2 [SP2]), pretreated patients with a VAS score of $<50 \mathrm{~mm}$ (SP6), and pretreated patients with a VAS score of $\geq 50 \mathrm{~mm}$ (SP8) is shown in Figure 2. Similar trends in change of AR treatment during the visit were reported for SP2, SP6, and SP8. The largest proportion of each subpopulation received a step-up in treatment. The most commonly prescribed medications during the consultation visit are listed in
Figure 3. The most common prescription was for a fixed combination of intranasal corticosteroid and antihistamine. The mean VAS of AR symptoms at the visit was $61.6 \mathrm{~mm}$. No adverse drug reactions were reported.

\section{Hungary}

Overall, data from 246 patients were documented. Patients were excluded because of a lack of confirmed data or missing therapy decisions $(n=18)$. Of the patients included in the study $(\mathrm{N}=228), 122$ were female $(53.5 \%)$. Most patients were aged 18 to 64 years $(193 ; 84.6 \%)$, with $12(5.3 \%)$ patients aged 12 to 17 years and $23(10.1 \%)$ patients aged 65 years or older. The mean age was 42.0 years (range, $13-84$ years). Within the last 7 days, $67.1 \%$ of patients had at least 1 AR treatment. The average time since the start of AR symptoms was 9.7 years. A total of 180 (78.9\%) patients reported a VAS of $\geq 50 \mathrm{~mm}$ for overall AR symptoms. Subpopulations are described in Table 3.

A total of 75 patients $(32.9 \%)$ had received no treatment within the last 7 days, whereas $74(32.5 \%)$ patients were treated according to step 1; $45(19.7 \%)$ patients were treated according to step 2; $33(14.5 \%)$ patients were treated according to step 3 ; and 1 patient $(0.4 \%)$ was treated according to step 4 . Among those patients treated according to step 3,75.8\% received a free combination of intranasal corticosteroid and oral or intranasal antihistamine (step 3a) and $24.2 \%$ received a fixed combination of intranasal corticosteroid and antihistamine (step 3b). Previous AR treatments are shown in Figure 4.

Among patients who rated their symptoms $<50 \mathrm{~mm}$ on the VAS, most patients received step 2 treatment, followed by no treatment in the previous 7 days (Table 4). Among patients who rated their AR symptoms as $\geq 50 \mathrm{~mm}$ on VAS, most patients received no treatment or step 1 medication (Table 4).

During the visit, 147 (64.5\%) patients were prescribed step 3 treatment, $60(26.3 \%)$ were prescribed step 2 treatment, $19(8.3 \%)$ were prescribed step 1 treatment, and 1 $(0.4 \%)$ patient each was prescribed step 4 treatment and no treatment. Among those patients prescribed step 3 treatment, $65.3 \%$ were prescribed a fixed combination, and $34.7 \%$ were prescribed a free combination of intranasal corticosteroid and oral or intranasal antihistamine.

The change of AR treatment during the visit in pretreated patients (SP2, pretreated patients with a VAS score of $<50 \mathrm{~mm}$ [SP6] and pretreated patients with a VAS score of $\geq 50 \mathrm{~mm}$ [SP8]) is shown in Figure 5. The medications most commonly prescribed during the consultation visit 


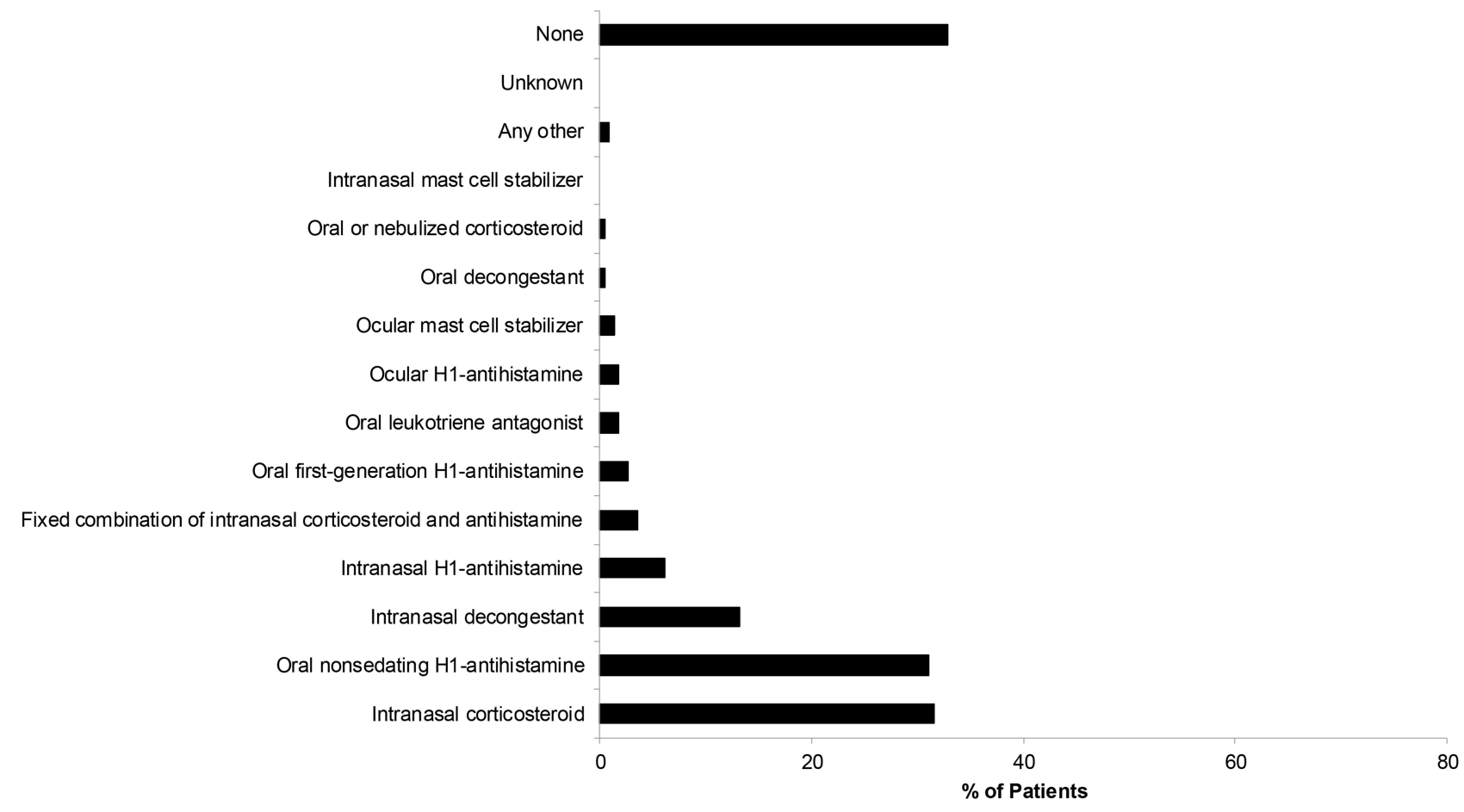

Figure 4 Previous symptomatic AR treatments within the last 7 days - Hungary. Multiple entries were possible.

are listed in Figure 6. The average VAS at the visit was $62.1 \mathrm{~mm}$. A single adverse event was reported $(0.4 \%)$, which was mild drowsiness after drug intake that resolved after 4 days. It was determined as possible causality for association with medication in the last 7 days (intranasal corticosteroid, oral first-generation H1-antihistamine).

\section{Discussion}

These results demonstrate that a majority of patients in our study population reported uncontrolled symptoms despite previous treatment, including those who used INCS or a free combination of INCS and antihistamines. Most patients with uncontrolled symptoms who had

Table 4 Previous Treatment per Step in Subpopulations Hungary

\begin{tabular}{|l|l|l|}
\hline $\mathbf{N}(\%)$ & $\begin{array}{l}\text { SP3: VAS }<\mathbf{5 0} \mathbf{~ m m} \\
\mathbf{N}=\mathbf{4 8}\end{array}$ & $\begin{array}{l}\text { SP4: VAS } \geq \mathbf{5 0} \mathbf{~ m m} \\
\mathbf{N}=1 \mathbf{8 0}\end{array}$ \\
\hline $\begin{array}{l}\text { No } \\
\text { treatment }\end{array}$ & I3 (27.1) & $62(34.4)$ \\
Step I & $9(18.8)$ & $65(36.1)$ \\
Step 2 & $17(35.4)$ & $28(15.6)$ \\
Step 3 & $9(18.8)$ & $24(13.3)$ \\
Step 4 & 0 & $1(0.6)$ \\
\hline
\end{tabular}

received previous AR therapy within the past 7 days received therapy modification according to the MACVIA algorithm. ${ }^{8}$ However, more than $27 \%$ (Hungary) and 40\% (Spain) of patients with uncontrolled symptoms who received previous therapy did not receive a step-up as suggested by the guidelines. This may have been the result of physician and/or patient preference to maintain the current treatment plan despite guidelines, or it may have been determined that poor AR symptom control was the result of patient nonadherence to the treatment plan and thus adherence should be improved before determining whether additional or different medication is necessary.

A considerable proportion of uncontrolled patients were prescribed multiple medications on the same step before being moved to the next step of AR therapy. In Hungary, the prescription decision was less dependent on whether patients were pretreated and more dependent on symptom severity. Most patients with a VAS of $\geq 50 \mathrm{~mm}$ received step 3 medication $(73 \%)$, whereas $50 \%$ of patients with a VAS of $<50 \mathrm{~mm}$ received step 2 medication. In Spain, the prescribing decision was less dependent on symptom control level (VAS) and more dependent on whether the patient was pretreated. During the visit, the most frequently prescribed medication was a fixed combination of intranasal corticosteroid and 


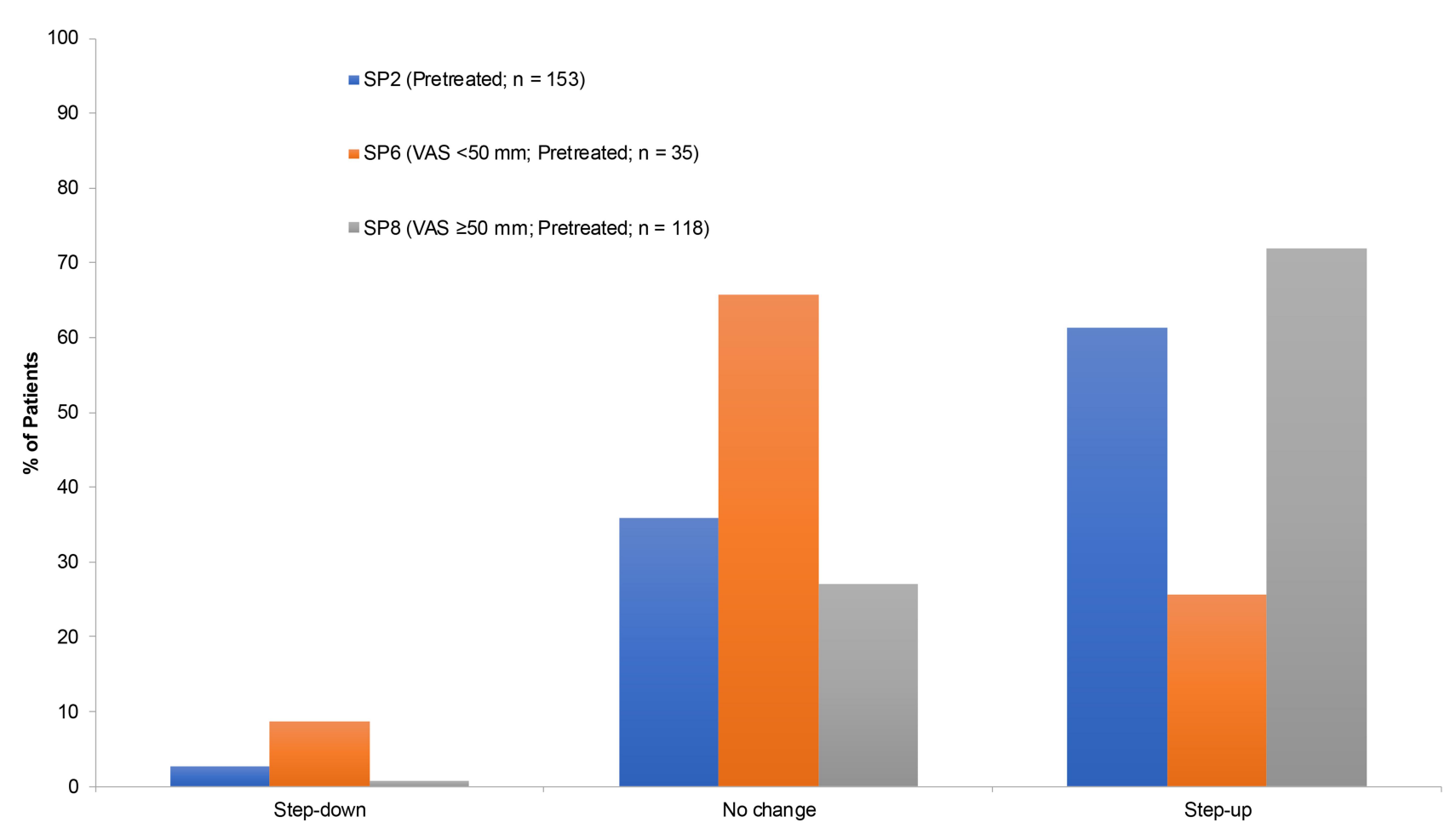

Figure 5 Change of AR treatment during the visit - Hungary.

intranasal antihistamine (step 3b, 65.7\%). Reasons for this prescribing decision may include the high rate of persistent $\mathrm{AR}$ and the high rate of pretreatment failure in Spain, which could require stronger treatment according to the treatment decision algorithm. According to the MACVIA clinical decision algorithm, ${ }^{8}$ all pretreated patients with a VAS of $\geq 50$

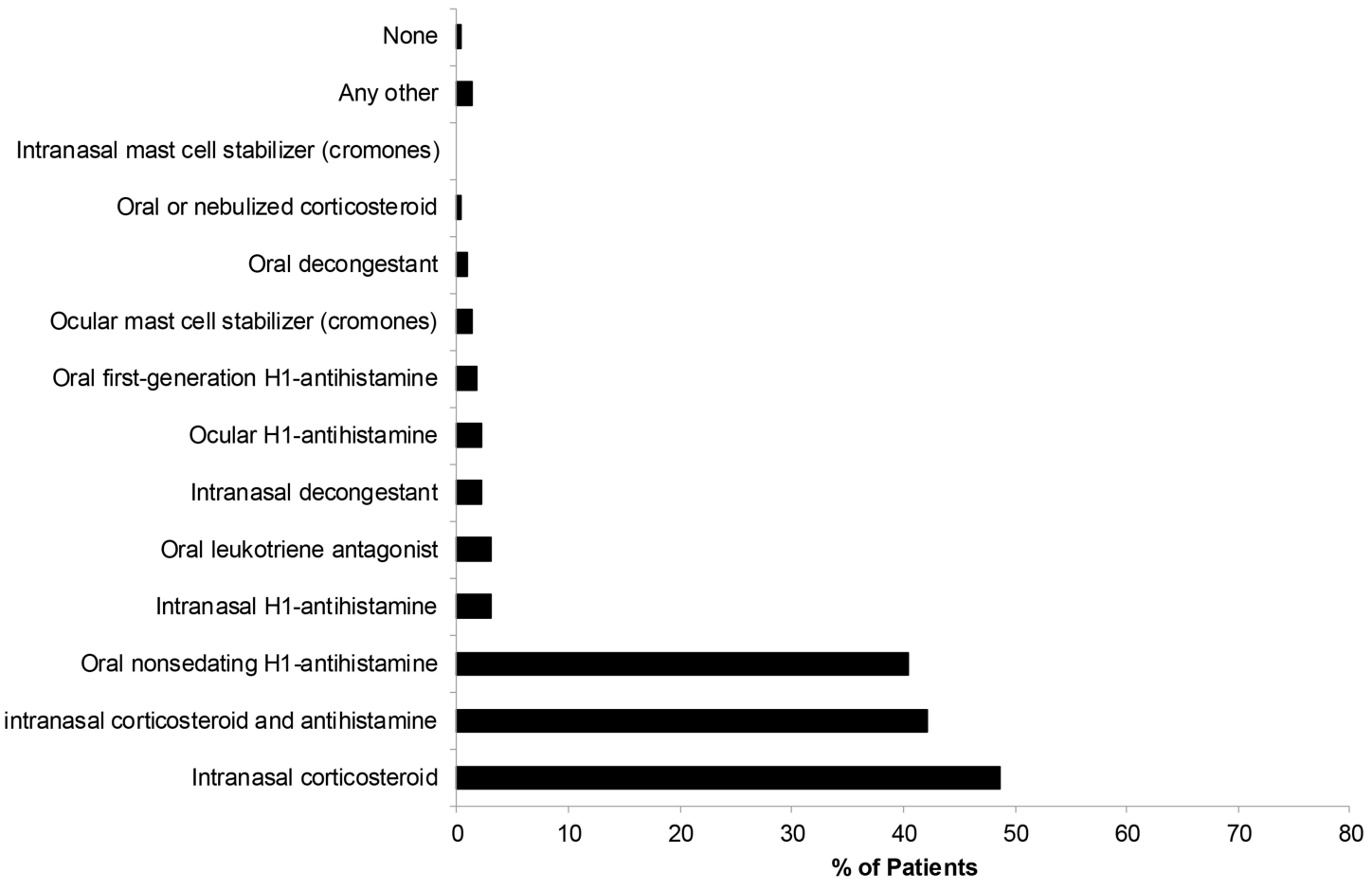

Figure 6 List of AR treatments prescribed during the visit - Hungary. 
$\mathrm{mm}$ (SP8) should receive step-up treatment, whereas pretreated patients with a VAS of $<50 \mathrm{~mm}$ (SP6) may receive either step-down/stop (if intermittent rhinitis/no allergen exposure) or maintain/step-up (persistent rhinitis or allergen exposure). This may explain why the individual decision in SP6 resulted in differences between countries.

Disease management may have also differed between countries for several other reasons, such as available treatment options, treatment access (reimbursement), and potential staffing of general practitioners vs specialists, who often prescribe differently.

Previous studies in other countries have reported a lack of adherence to guideline-recommended management of $\mathrm{AR}$, as well as reports of underdiagnosis and undertreatment of AR that support our results. For example, in 1277 Danish adults, 122 of 280 (43.6\%) people with AR had not received treatment in the past 12 months and $43.4 \%$ had not received a diagnosis. ${ }^{19}$ In a random sample of 726 adolescents and adults in Copenhagen, Denmark, $83 \%$ of patients were undertreated and $32 \%$ were undiagnosed. ${ }^{20}$

The use of the VAS has been a guideline recommended for years to improve the management of AR, because physicians often underestimate patient burden, which leads to undertreatment. ${ }^{6,19}$ Therefore, using the VAS may improve communication between physicians and patients, which will allow for the correct assessment of disease burden and, consequently, the appropriate AR management/symptom control.

Although MACVIA was the current treatment algorithm at the time of the survey, ${ }^{8}$ the treatment guidelines have since been updated. Based on the current ARIA guidelines, a free combination of INCS plus OAH (used as step 3a medications in this study) was not found to be more effective than INCS alone and therefore would be considered as step 2. ${ }^{7}$ Based on study results, many patients using step 3a medications were uncontrolled and switched to step $3 b$ (fixed combination of INCS plus INAH) during the consultation, which supports the current ARIA algorithm.

This study has several limitations. As it was an observational study in a real-life setting of a convenience sample, there is potential for the presence of confounding bias. It must be noted that there is a potential bias toward patients with a higher disease burden, since patients were presenting to their clinician with acute AR symptoms and therefore may not be representative of the broader population with AR. In the current study, symptom control was assessed using VAS measurements that were then used to make step-up or step-down decisions for treatment; however, several factors could have influenced clinicians' treatment decisions, including length and type of previous treatment, assessment of correct medication delivery technique, patient adherence to treatment, and patient preferences. Furthermore, it is likely that some patients were experiencing seasonal triggers during the study period that may have affected treatment decisions. In Spain, tree pollen is active from January to May and weed pollen is active from June to November; in Hungary, ragweed pollen peaks in August to October, whereas other pollen levels are elevated from February through June. The rationale for treatment decisions was not assessed in the current study. Future studies may gather more information regarding AR control by assessing VAS changes with previous and future treatments, and effects on quality of life using the Rhinoconjunctivitis Quality of Life Questionnaire, which were beyond the scope of the current study.

\section{Conclusions}

These data underscore the need for physician education to improve AR management and control in accordance with consensus treatment guidelines. Improvement of communication between patients and physicians is needed to facilitate more appropriate diagnosis and treatment decisions.

\section{Abbreviations}

AR, allergic rhinitis; ARIA, Allergic Rhinitis and its Impact on Asthma; a nongovernmental organization; INAH, intranasal antihistamine; INCS, intranasal corticosteroid; MACVI, Contre les MAladies Chroniques pour un VIeillissement Actif (fighting chronic diseases for active and healthy ageing), a reference site of the European Innovation Partnership on Active and Healthy Ageing; $\mathrm{OAH}$, oral antihistamine; SD, standard deviation; SP, subpopulation; VAS, visual analog scale.

\section{Data Sharing Statement}

The datasets used and/or analyzed during the current study are available from the corresponding author on reasonable request.

\section{Ethics Approval and Consent to Participate}

The investigation represented a noninterventional survey as defined by European regulations (ie, the rules imposed for this survey plan did not interfere with the physician's common therapy). The study was carried out in accordance with 
the national laws and guidelines current at that time for conducting noninterventional studies and was approved by local ethics committees in Spain on May 9, 2018 (C.I. EPA18/026) Comité de Ética de la Investigación de la Comunidad Autonóma de Aragón and in Hungary on September 22, 2017 (OGYÈI/37070-11/2017) OGYEI, Országos Gyógyszerészeti és Élelmezés-egészségügyi Intézet.

\section{Statement of Compliance}

All procedures performed in studies involving human participants were in accordance with the ethical standards of the institutional and/or national research committee and with the 1964 Helsinki Declaration and its later amendments or comparable ethical standards. Informed consent was obtained from all individual participants involved in the study.

\section{Acknowledgments}

We would like to thank the patients who participated in the trial. This paper was presented at the European Academy of Allergy \& Clincial Immunology (EAACI) 2019 as a poster with interim findings: http://webcast.eaaci.cyim. com $/$ mediatheque $/$ media.aspx $?$ mediaId $=66705 \&$ channel $=$ 8518. The poster's abstract was published in the European Journal of Allergy and Clinical Immunology: https://onli nelibrary.wiley.com/doi/10.1111/all.13961.

\section{Author Contributions}

GG, ME, AK, FK, DTN, and HCK have made substantial contributions to the conception or design of the work; or the acquisition, analysis, or interpretation of data for the work: drafting the work or revising it critically for important intellectual content; provided final approval of the version to be published; and are in agreement to be accountable for all aspects of the work in ensuring that questions related to the accuracy or integrity of any part of the work are appropriately investigated and resolved.

\section{Funding}

The design of the study and collection, analysis, and interpretation of data was funded by MEDA Pharma GmbH \& Co. KG (a Mylan Company), Bad Homburg, Germany. Technical, editorial and medical writing assistance was provided to the authors by Erin Burns, $\mathrm{PhD}$ and Strategix, an affiliate of The Lynx Group LLC; funding for this support was provided by MEDA Pharma $\mathrm{GmbH} \&$ Co. KG (a Mylan Company).

\section{Disclosure}

GG was a paid consultant and speaker for AstraZeneca, Chiesi, BMS, MSD, Berlin-Chemi, Boehringer Ingelheim, Roche, Novartis, Pfizer, Orion, including Ipsen, and Mylan as a speaker. ME is an employee of MEDA Pharma $\mathrm{GmbH}$ \& Co. KG (a Mylan Company). AK is a Mylan, Inc. employee and shareholder. AK has also been employed at Novartis and Lundbeck pharmaceutical companies. FK is an employee of MEDA Pharma GmbH \& Co. KG (a Mylan Company). DTN is an employee of MEDA Pharma $\mathrm{GmbH} \&$ Co. KG (a Mylan Company). HCK worked as a paid consultant for AstraZeneca, Boehringer Ingelheim, Chiesi, GSK, and Novartis. The authors report no other conflicts of interest in this work.

\section{References}

1. Bousquet J, Khaltaev N, Cruz AA, et al. Allergicrhinitis and its impact on asthma (ARIA) 2008 update (in collaboration with the World Health Organization, GA ${ }^{2}$ LEN and AllerGen). Allergy. 2008;63(suppl 86):8-160.

2. de la Hoz Caballer B, Rodríguez M, Fraj J, Cerecedo I, AntolínAmérigo D, Colás C. Allergic rhinitis and its impact on work productivity in primary care practice and a comparison with other common diseases: the cross-sectional study to evAluate work productivity in allergic rhinitis compared with other common diseases(CAPRI) study. Am J Rhinol Allergy. 2012;26(5):390-394. doi:10.2500/ ajra.2012.26.3799

3. Marseglia GL, Caimmi S, Marseglia A, et al. Rhinosinusitis and asthma. Int J Immunopathol Pharmacol. 2010;23(1 suppl):29-31.

4. Romano MR, James S, Farrington E, Perry R, Elliott L. The impact of perennial allergic rhinitis with/without allergic asthma on sleep, work and activity level. Allergy Asthma Clin Immunol. 2019;15(1):81. doi:10.1186/s13223-019-0391-9

5. Kuiper JR, Hirsch AG, Bandeen-Roche K, et al. Workplace indirect cost impacts of nasal and sinus symptoms and related conditions. $J$ Occup Environ Med. 2019;61(8):e333-339. doi:10.1097/ JOM.0000000000001636

6. Price DB, Scadding G, Bachert C, et al. UK prescribing practices as proxy markers of unmet need in allergic rhinitis: a retrospective observational study. NPJ Prim Care Respir Med. 2016;26(1):1-8. doi:10.1038/npjpcrm.2016.33

7. Bousquet J, Schünemann HJ, Togias A, et al. Next-generation Allergic Rhinitis and its Impact on Asthma (ARIA) guidelines for allergic rhinitis based on Grading of Recommendations Assessment, Development and Evaluation (GRADE) and real-world evidence. J Allergy Clin Immunol. 2020;145(1):70-80. doi:10.1016/j.jaci.2019.06.049

8. Bousquet J, Schünemann HJ, Hellings PW, et al. MACVIA clinical decision algorithm in adolescents and adults with allergic rhinitis. $J$ Allergy Clin Immunol. 2016;138(2):367-374. doi:10.1016/j. jaci.2016.03.025

9. Klimek L, Bergmann KC, Biedermann T, et al. Visual analogue scales (VAS): measuring instruments for the documentation of symptoms and therapy monitoring in cases of allergic rhinitis in everyday health care: Position Paper of the German Society of Allergology (AeDA) and the German Society of Allergy and Clinical Immunology (DGAKI), ENT section, in collaboration with the working group on Clinical immunology, Allergology and Environmental Medicine of the German Society of Otorhinolaryngology, Head and Neck Surgery (DGHNOKHC). Allergo J Int. 2017;26:16-24. doi:10.1007/s40629-016-0006-7 
10. Bousquet PJ, Demoly P, Devillier P, Mesbah K, Bousquet J. Impact of allergic rhinitis symptoms on quality of life in primary care Int Arch Allergy Immunol. 2013;160(4):393-400. doi:10.1159/ 000342991

11. Yamamoto H, Yamada T, Sakashita M, et al. Efficacy of prophylactic treatment with montelukast and montelukast plus add-on loratadine for seasonal allergic rhinitis. Allergy Asthma Proc. 2012;33(2):e17e22. doi:10.2500/aap.2012.33.3514

12. Baldacci S, Maio S, Angino A, et al. Determinants of non-adherence to pharmacologic allergic rhinitis treatment. Paper presented at: 2013 European Respiratory Society Annual Congress; September 7-11; 2013; Barcelona, Spain. Abstract 5241. Available from: https://erj. ersjournals.com/content/erj/42/Suppl_57/P3839.full.pdf. Accessed October 22, 2020.

13. Bukstein D, Luskin AT, Farrar JR. The reality of adherence to rhinitis treatment: identifying and overcoming the barriers. Allergy Asthma Proc. 2011;32(4):265-271. doi:10.2500/aap.2011.32.3455

14. Usherwood T. Encouraging adherence to long-term medication. Aust Prescr. 2017;40(4):147-150. doi:10.18773/austprescr.2017.050

15. Ryan D, van Weel C, Bousquet J, et al. Primary care: the cornerstone of diagnosis of allergic rhinitis. Allergy. 2008;63(8):981-989. doi:10.1111/j.1398-9995.2008.01653.x
16. Loh CY, Chao SS, Chan YH, Wang DY. A clinical survey on compliance in the treatment of rhinitis using nasal steroids. Allergy. 2004;59(11):1168-1172. doi:10.1111/j.1398-9995.2004.00554.x

17. Hellings PW, Dobbels F, Denhaerynck K, Piessens M, Ceuppens JL, De Geest S. Explorative study on patient's perceived knowledge level, expectations, preferences and fear of side effects for treatment for allergic rhinitis. Clin Transl Allergy. 2012;2(1):9. doi:10.1186/ 2045-7022-2-9

18. Greiner AN, Hellings PW, Rotiroti G, Scadding GK. Allergic rhinitis. Lancet. 2011;378(9809):2112-2122. doi:10.1016/S0140-6736(11) 60130-X

19. Grønhøj Larsen C, Gyldenløve M, Linneberg A. Allergic rhinitis is often undiagnosed and untreated: results from a general population study of Danish adults. Clin Respir J. 2013;7(4):354-358. doi:10.1111/crj.12015

20. Nolte H, Nepper-Christensen S, Backer V. Unawareness and undertreatment of asthma and allergic rhinitis in a general population. Respir Med. 2006;100(2):354-362. doi:10.1016/j.rmed.2005.05.012

\section{Publish your work in this journal}

The Journal of Asthma and Allergy is an international, peer-reviewed open-access journal publishing original research, reports, editorials and commentaries on the following topics: Asthma; Pulmonary physiology; Asthma related clinical health; Clinical immunology and the immunological basis of disease; Pharmacological interventions and new therapies. The manuscript management system is completely online and includes a very quick and fair peer-review system, which is all easy to use. Visit http://www.dovepress.com/testimonials.php to read real quotes from published authors. 